Western University Scholarship@Western

FIMS Publications

Information \& Media Studies (FIMS) Faculty

2012

\title{
Public library use of free e-resources
}

Heather Hill

Western University, hhill6@uwo.ca

Jenny Bossaller

University of Missouri

Follow this and additional works at: https://ir.lib.uwo.ca/fimspub

Part of the Library and Information Science Commons

Citation of this paper:

Hill, H. \& Bossaller, J. (2013) Public Library Use of Free E-Resources. Journal of Librarianship \& Information Science 45(2) 103-112. 


\section{Introduction}

This paper describes a three-part study that was conducted over a period of one year examining the use of free e-resources by public libraries. Talk of a library without walls has encouraged librarians, for years now, to employ innovative methods to reach beyond the bricks and mortar library to library users and potential users on the Internet. Collection development has become increasingly relegated to vendors, and at the same time online publishing has exploded. Online vendors such as NetLibrary and Overdrive have stepped in to guide librarians' selection of ebooks. There are many free online resources on the Internet, though. This scenario led to the question at the root of this project: have librarians connected their library users to the best, free e-resources, and how are they doing it? Are there existing digital collections that might aid librarians in developing their online collection, and are they using these?

When the conversation falls to digitization, Google Books receives most of the attention. But Google is not the only participant in the conversation. There are many other large scale digitization projects that make material freely available online such as Project Gutenberg, the Internet Archive, and the American Memory Project. Robert Darnton, in his 2009 essay "Google and the future of books," politely dismisses these types of projects as "minute and ineffective in comparison to Google" (2009, p. 17). Darnton is correct in stating that other digitization projects lack the wealth of Google and are not on equal footing with its size, but are these projects actually minute and ineffective? The specific lens for considering this question is the public library and how they are using these types of free resources. Might it be prudent, in this day and age, to rethink traditional collection development in existing public libraries? Collection development, after all, relies on the notion that libraries want to provide the best sources to their publics. Could some of these best resources be freely available online materials?

\section{Literature review}


The library and the librarian in the information age

There have been varied predictions about the fate of the library in the 21 st century, which has resulted in an uneasy or mixed relationship between librarians and the internet. The life of the Library (as an institution), after all, has been intertwined with that of paper and print. In the 1990 's there were predictions that the internet would render libraries obsolete.

Criticising the concept of paper equaling obsolescence in the digital age, Eco (1994) noted:

"There is a confusion about two distinct questions: (a) will computers make books obsolete? and (b) will computers make written and printed material obsolete?.....I am pretty sure that new technologies will render obsolete many kinds of books, like encyclopedias and manuals...[but]...books will remain indispensable not only for literature......the idea that a new technology abolishes a previous role is much too simplistic."

Miksa (1996, p.111) noted the challenges of the digital age as well as the opportunities.

To me the chief issue is not to devise strategies which the modern library...can use to preserve itself against such change, as if [it was] some sort of sacred cow which must continue in [its] original form at all costs. Rather, it is to identify the significant aspects of the new environment which give the most promise for assisting in the creation of a new library era, for assisting in the transformation of the modern library into a new expression of the library in society.

Levy (2003, p. 25) begins his chapter with the question "What are libraries in a digital age? What function do they serve at a time when whole new classes of materials-digital materialsappear to be taking center stage?" This question necessitates an exploration of how libraries have adapted to changing formats and media. The guiding actions for libraries should be to 
collect, organize, and preserve documents, no matter what form they take. As Buckland (1997, p. 30) said, "Documents are talking things." They are communicated thoughts that we can collect, organize, and preserve. It matters little what format they take.

Despite that optimistic thought, there are still doubts about what role the physical library will have as digital services become increasingly important. D'Elia et. al. (2002) conducted a telephone survey study with the intention of describing the relationship between internet and public library use. They found some compelling reasons people gave for not using the public library, including lack of time, distance issues, and preferences for purchasing their own material, but their conclusions are far from pessimistic for the library. They concluded that "these analyses do not seem to provide evidence...that the reasons for not using the library are affected by use of the internet" (p. 815). Instead, they found that library and internet use are complementary; in general, frequent internet users also frequent the public library.

Since Eco, Buckland, Miksa's and the other writings above, public libraries have incorporated more e-books, electronic subscriptions, and free online materials into the collection. The increasingly important role that such materials play in the library have necessitated advances in cataloging, the traditional means of access to the materials.

Gorman (2003, p. 459) described four levels of documents in a library collection:

- Locally owned physical documents

- Physical documents owned by other libraries but available through ILL;

- Purchased or described to electronic documents;

- "Free" electronic documents. 
This has been called the "hybrid library...found on the continuum between the conventional and the digital library...designed to bring a range of technologies from different sources together in the context of a working library" (Baruchson-Arbib and Bronstein 2002, p. 398).

Public libraries have been experiencing increasing demands for more electronic content, particularly in the form of ebooks. Commercial entities (such as NetLibrary and Overdrive) have already stepped in to provide access to public domain texts as part of their subscription packages. Additionally, while there seems to be a preference for package deals, there is still a desire for selecting individual titles deemed of use (Blummer 2006). The advantage of providing access through a commercial vendor is uniformity and easily uploaded catalog records. However, vendors only provide access to a portion of the freely available texts that are available, and users generally have to be affiliated with the institution and log in in order to access the public domain works. The Boston Public Library has taken the lead in circumventing the login issue with its collaborative project with Overdrive. Thousands of Project Gutenberg items, with adequate metadata, have been added to the website and made openly available. This results of this collaboration represent a strong tool for alerting Boston Public Library patrons to these resources.

\section{free resource studies}

There has been little formal evaluation on the use of free electronic resource use by libraries, and much of the discussion in the literature has focused on academic libraries' use of ebooks (see - Soules 2009, Connoway and Wicht 2007, Hutton 2008, Perrone 2009, Rodzvilla 2009, Ball 2009, Tedd 2005). The few public library perspectives focus mainly on subscription ebooks (see - Duncan 2010, Currie and lacobucci 2010, Dierks 2010). 
Jones (2010) tried to determine if the public domain books in Google Books could constitute a viable research collection. He found that the pre-1872 content available in Google Books approximated or was superior to some American research library collections.

Hutton (2008) studied the presence of free ebook titles in academic library catalogs. In searching for ten titles in ten OPACs, she found that "e-book title listings in library catalogs were limited" (p. 502). While some libraries directed library patrons to online collections via a separate page of 'digital resources', most did not include the records in their catalog. Significantly, she notes that "Some academic libraries obtain e-book catalog records from vendors such as NetLibrary...Access to the texts via NetLibrary presents the irony of libraries paying for freely available content. In addition, vendors frequently limit the number of concurrent users for a title, paradoxically limiting access to open content" (p. $502-503)$.

Beall (2009) examined the University of Michigan's partnership with Google Books to digitize and create MARC records for over 100,000 public domain items. Beall asked, is it "worthwhile to load records in a local OPAC when the material is already accessible elsewhere on the internet" ( p. 453)? Importantly, he stated, "there was concern about loading the [books'] records because the resources they link to are under the control of others" (p. 455). He concludes that it was worth the significant effort and data manipulations because the books filled gaps in their collection, and gave patrons access to books that were otherwise only available in an unpopular microfilm collection. "It is likely that sets of records for open-access, digitized books will increase in availability...for [these] books, the only expense will be the cost of buying and loading the MARC records..." (p. 461).

There is evidence that including ebooks in the catalog does increase usage. Dillon (2001) examined the use of an ebook collection before and after the titles were catalogued at the University of Texas. After the records were added users "increased the total number of titles that 
they had read in this collection to 34 percent in less than three months, an increase...of almost 50 percent" (p. 357). Comparing three months before they were added to the consortial catalog to the three months afterward, there was in increase in usage of over 100 percent.

Bedord (2009) points out that "The major key to the success of ebooks as an emerging industry is continued growth in the number of titles" (p. 18). This wide availability, and "inclusion in the library OPAC" are very important for e-book success. Bedord continues (p. 18):

Inclusion in the library OPAC is another major key. Initial implementations for ebooks were generally in a separate section on the libraries' websites, in much the same way videos and computer games were added. This separation resulted in low usage. Users were looking for answers first and format second; they were unaware that there might be immediate ebook alternatives. Usage went up dramatically when ebooks were included in the main catalog (and the number of titles increased!).

It is this confluence of change--technological improvements, increased availability, and attitude toward cataloging of ebooks, that will determine libraries' success in integrating online resources into the library's information ecology. Librarians have adapted services and sources to accommodate the public's information seeking and pleasure reading needs, investing more heavily in electronic resources, often as an alternative to maintaining the physical collection. In addition, librarians have taken advantage of the possibilities offered by the web by digitizing archival collections. Beyond efforts like Boston Public Library's, and taking into consideration the possible cataloging and concomitant budgeting issues inherent in further developing free resource collections as laid out above beg the question: how are public libraries increasing access to these types of materials to their communities? 


\section{Study}

This multi-stage project evolved from an interest in how free resources are perceived in public libraries and how public libraries are directing library users to these sources. Of particular interest were public libraries that have these types of materials in their catalogs. What and how many of these types of materials are being added? If libraries have acknowledged the legitimacy of these resources by actively collecting them, are those works treated as part of the collection? Or, are they on a separate web page a printed pathfinder or some combination? How are library users alerted to these resources?

\section{Methods}

The project evolved in three distinct stages. The first stage involved searching WorldCat for records from three large-scale projects: Project Gutenberg, the Internet Archive, and materials with Creative Commons licenses and examining public libraries attached to these records. The second part was an exploratory survey sent to the public libraries that had multiple records for materials from the free projects as indicated in WorldCat. The third part was a survey disseminated through professional listservs and libraries randomly selected from the American Library Directory.

\section{WorldCat analysis and findings}

The focus for the WorldCat analysis was on textually based resources in the form of freely available ebooks. In the fall of 2010, the researchers searched WorldCat for Project Gutenberg and the Internet Archive related titles using the notes fields.

Creative Commons licensed materials are less likely to be easily identified through such means, so an alternate approach was taken. A list of Creative Commons licenced titles was identified through personal knowledge, a partial list on the Creative Commons Wiki, and the 
additions made to the Nebraska Library Commission's OPAC which has taken a strong initiative in adding Creative Commons licensed materials.

Texts included traditionally published materials that were currently under copyright protections, titles where copyright had reverted from publisher back to author, titles from vanity presses, public domain works, and some fan fiction. The subject areas covered by these projects varied widely and included open publishing, fiction, manuals and handbooks, statistics and mathematics textbooks, biodiversity, technology, and copyright and the public domain. Each title was then searched in WorldCat.

In looking at the broader picture of how these three projects, as wholes, are represented it was initially assumed that Google Books, which seems to be more constantly in the public eye, would be much more prevalent than the three projects of interest, but that turned out not to be the case. When examining WorldCat to compare the prevalence of the four projects, Google Books is linked to the least. 96 libraries (7 of which are public libraries) have added records for Project Gutenberg, 87 (3 of which are public libraries) have added a record for the Internet Archive, 5 have added records for the Creative Commons website, and 4 have added Google Books.

The most popular record in WorldCat from these three projects is CREW: $A$ weeding manual for modern libraries by Jeanette Larson. 46 libraries are linked to its record. The majority are public libraries, but there are also five state and two college libraries. This finding brings two thoughts; one, that public libraries are taking advantage of the access to an item that is quite beneficial to managing the library, but possibly not those titles of interest to patrons. The CREW manual is a well known and used collection development text. There is little doubt that having this text easily on hand, and free, through its Creative Commons license benefits the library. But for all but one of the 46 libraries, this is the only record from these projects that these 
libraries have uploaded to WorldCat. It seems that while these libraries are willing to add this particular resource relevant mainly to the library staff, they may not be taking advantage of other available texts of possible interest to patrons.

In general, smaller systems may have one or two records and these are most often items from the Internet Archive. These libraries are not generally linking to textual materials, but are instead focused much more on some of the archived web content available. Popular records are those related to the September 11th Archive, the 2002 elections archive, the NASA image archive, and the International Children's Digital Library. As three of the four most popular resources are of a non-textual focus, these public libraries may have a stronger interest in borndigital information.

Large public library systems are much more likely to not only have records for items from these projects, they were also more likely to have their own digital initiatives whether adding materials to the Internet Archive or in simply adding digital materials to their libraries' collections. The largest public libraries, Boston Public Library, Toronto Public Library, New York Public Library, and the Allen County Public Library Genealogy Center in Indiana have digitized and submitted thousands of texts to the Internet Archive.

These large libraries are actively cooperating with the Internet Archive and each have scanning stations in-house to digitize items from their collections. Their efforts have not been insubstantial. The Boston Public Library has made more than 24,631 items available through the Internet Archive including works in English, Spanish, Italian, and German. Toronto Public Library has added more than 810 texts including sessional papers from Parliament. The New York Public Library has added 135,960 items. The Allen County Public Library in Indiana has 46,136 items in the Internet Archive including government documents and other information of interest to genealogical research. 
WorldCat provided a place to begin searching for aggregated data from these projects, but also provided three significant drawbacks. First, gaining a firm sense of how many libraries used the resources is difficult because there is no way to limit a search in WorldCat by library type. As such, analysis focused primarily on the most popular records from these projects as opposed to all of them. Second, some public libraries do not upload their records for these types of materials to Worldcat in order to defer erroneous ILL requests. Finally, other libraries may have uploaded records for items from these projects, but not noted the projects as the source of the material. Because of these impediments, the focus was on gaining an initial impression about the most popular resources utilized.

\section{Exploratory survey and findings}

The exploratory survey was sent to 34 public libraries identified in the initial WorldCat search as being some of the most active in uploading records to WorldCat for the three projects of focus in the first phase of the study. The survey consisted of a mix of quantitative and qualitative questions geared towards developing an understanding of how freely available ebooks and etexts are being used and by whom. There was a total of eleven responses, yielding a $35 \%$ response rate. Discrepancies in percentages are due to respondents not answering all questions. Most (70\%) of the respondents say they are very interested in ebooks--on a scale of one to five, they are a five.

Seventy percent of respondents said that patrons were "somewhat" willing to use ebooks. Part of the hesitancy inherent in this answer could be arising because of format restrictions, non-integrated collections and publisher restrictions. One librarian expressed frustration over non-integrated collections, "Patrons only find ebooks we currently have if they see link in library catalog--only have a few titles currently.”. 
Considering that access to e-resources can only be truly equitable if the library provides a means of access to patrons, are these libraries providing devices to their user community? Thirty percent of the libraries loaned laptops and ten percent loaned ebook readers. The primary reason given for not loaning either is because of the expense, several cited budget problems, and fear that they would be lost or broken: "We've been somewhat leery of a project like this, which might have lots of technical issues but have not entirely ruled out the possibility of loaning of ereaders," and "We're thinking of lending some ereading devices...but only [a few]. They will be a drop in the bucket. Like laptops, Ereaders are both expensive and breakable."

There is some indication that collecting ebooks is not seen as part of regular collection development. There was some variability in the title of the person who was responsible for developing the ebook collection. Three (30\%) said that the multimedia, or audio-visual, manager was responsible for selection of online materials. This might indicate that ebooks are not falling under the general collection, but are being thought of as an extension of technology. In other words, their format (rather than content) is dictating who is responsible for their collection and maintenance.

Unsurprisingly, most libraries (77.8\%) plan to continue to develop their ebook collection. When asked how they determine which digital materials to include in the collection, they mentioned patron demand, popularity, etc., but two responses stood out: "[we] will probably consult with Overdrive about what else is available," indicating a focus on popular new materials, a reliance on subscription ebook access as the predominant focus, the limitations of what is available, and a possible abdication of responsibility in selection. The second response seems to indicate an active digitization program, "patron demand, curator interest, and special event interest." 
The focus of the second survey broadened, based on the results of the previous survey and a desire to widen the focus beyond free ebooks to free online resources. Popular, free e-projects identified in the WorldCat analysis were used as part of the basis for the survey. Seventy-five librarians responded to the second survey. The majority of participants were from the United States, with three from Canada. There was broad representation in both type and size of community served with comparable numbers of urban, suburban, and rural libraries participating and a spectrum from very large to very small libraries.

\section{policies and perspectives}

Are free electronic resources currently a part of the libraries' institutional culture? Inclusion in library policy--either explicitly in a collection development policy or implicitly in the librarians' perspectives on such sources served to indicate positive presence in the institutional culture. Seventy-seven percent of the respondents reported that it is their library's policy to collect or link to free digital collections or websites.

Of those who were positive about the inclusion of free resources, several cited free resources as a way to expand their collection during tough economic times. Access was pegged as either a supplement to a small physical collections and facilities or as a way to extend library service beyond the normal operating hours.

"Too many resources are available online for free. We are a small public library system. It's a waste of money to purchase materials that patrons can access online for free"

"As a small public library, we have limited budget and shelf space in a....Carnegie building. Free e-book collections allow our patrons the opportunity to access titles we may not have room to shelve in the library..." 
"Our library is much too small for our actual user base, so we have to switch to digital resources; plus we try to support e-government services for patrons that don't have computers so that adds to our needs for "free" digital collections"

A high proportion of respondents (77\%) reported that collecting free e-resources is part of their library policy, but there are indications that the policy may be either unwritten, vaguely defined, or a relatively lax interpretation of policy--for example: "It is not "policy" but we have recently linked to two free digital collection websites because we were not subscribing to any ebook vendors." Only $16.1 \%$ of the respondents stated that free online sources are mentioned explicitly in their library's collection development policy. Additionally, only $24 \%$ considered these types of resources to be part of their library's collection.

Of the respondents who reported that it is not their library's policy to collect and link to free sources, a variety of impediments and a particular perspective of what library service should be were cited as reasons. The most commonly reported impediment was the timeintensive nature of the task. "[We] don't have time only have part time cataloguer" [sic]; it is too "difficult to assure all links remain visible." Other barriers come in the form of consortium policies that vary from what an individual library would prefer. "Our library is part of a consortium which may have different policies that our single library. We would like to link to free stuff in the cooperative catalog, but there are many obstacles to making that a reality" [sic]. Interestingly, $22.6 \%$ stated they do not plan to add any more free online sources to their collection in the future.

For one respondent, the decision not to focus on free resources reflected what was thought to be most useful for patrons: "We do currently think it is worthwhile or feasible to link to websites in our catalog, but rather prefer to focus our energies and time on quality web searching with/for patrons, and using resources like the Internet Public Library to organize and 
verify the quality of internet resources." This indicates more of a hands-on approach to information services. It is also in contrast to one respondent who stated it was their library's policy to collect free resources but, "We do not do this extensively because we think the content is often most discoverable through search engines such as Google" [sic].

\section{providing access}

There are a number of ways that libraries might provide links to quality e-resources: through a list of sources from a web page, handouts or pathfinders, through the catalog, or a federated search overlay product. There are advantages and drawbacks to each choice. For instance, a list of e-resources, online or on paper, is beneficial for labor and maintenance costs, but adds another layer of searching for patrons. Adding these resources to the catalog or through a federated search allows patrons the convenience of one search, but the setup and maintenance could be significant deterrents.

In looking at a few particular types of free resources like e-book projects, local or regional archival projects, business resources, and government resources, web pages are still the predominant access point libraries add to connect patrons to these resources. $91.8 \%$ of surveyed libraries link to business resources on a web page, followed by government resources (90.8\%), local or regional archives (87\%), and national archival projects (83.3\%).

The OPAC comes in second and is most often used for long-term, stable resources like Project Gutenberg (27.1\%), local or regional archives (25.9\%), and government resources (23.1\%). Few participants offer access through any kind of federated search. The participants were least likely to use a printed pathfinder, but business resources were the most likely candidate to have a printed pathfinder, with $27.9 \%$ of libraries providing pathfinders for business resources. 
Some participants mentioned other specific types of resources of interest to their patrons including health or medical sources $(n=8)$, such as Medline Plus, The Mayo Clinic, and John Hopkins; local or regional interest and recreation (7); literary resources (5), such as book club or reader's advisory databases; employment resources (4); directories (4); legal resources (4);education (4); and arts.

Insert table 1 here

The focus for the survey was also to develop a broad understanding of what resources libraries are most likely to connect to. Specific projects identified as popular during the WorldCat analysis were included in the survey. Literary, medical, and reference have the strongest representation. Project Gutenberg, the Internet Archvie, and Google Books are all in the top six resources, Pubmed is the second most popular resource and the Internet Public Library is the third.

Our initial finding, that Google Books was not the most popular resource, was confirmed by the survey. Survey participants noted that Google Books was not the most frequently utilized tool and placed this resource 6th in popularity, after Project Gutenberg, PubMed, the Internet Archive, the Internet Public Library (IPL) and the American Memory Project.

Insert table 2 here

the collection and free resources 
Budgetary constraints are one cause for libraries to reconsider the role of free online sources as a part of their collection. $60 \%(n=45)$ respondents said that their library has had to cut back on purchases for their collection and $26.6 \%(n=20)$ have used free online sources as replacements for previously purchased materials.

Specific sources that have replaced purchased materials are government sources $(n=9)$, including the CIA World Factbook, CQ Roll Call, local directories, federal directories, GPO, the Occupational Outlook Handbook, noaa.gov and tax forms. Medical sources were a close second $(n=7)$ and elicited some unsurprising comments, "I don't order as many expensive reference materials" as well as some more interesting ones. "Users seem more receptive to names of medical institutions [such as Johns Hopkins or the Mayo Clinic] than to a database"; " "Our consortium declined to purchase Medline from EBSCO". Automotive related sites were mentioned by four respondents (replacing the Kelly Blue Book and auto repair books). Other subject areas where free online resources have taken the place of previously purchased materials are business, financial sources, directories, legal resources, entertainment, test preparation materials, literature and language, and maps.

usage by community

Participants were asked to list the resources they felt were most important to provide to their patrons as well as the ones used most often by their communities.

A dwindling budget isn't the sole reason for shifting to free online resources; the trend is also driven by other issues such as the shift in government publishing and changes in patron expectations. Government publications are increasingly moving online. In addition, public libraries are now one of the few places that provide tax forms to the public. Government sites and tax forms were most often mentioned in response to both questions. Genealogy information, employment resources, medical/health sites, and local/regional information were 
cited frequently. There was significant overlap in answers between these two questions, although literary sources (particularly free e-books) and educational sources were more often mentioned as sources promoted by the library.

Some respondents mentioned specific sources, such as the Internet Public Library and MedLinePlus. Nine respondents reported that they don't collect data or don't know of any way to measure what is most important to their patrons.

\section{Discussion}

The research so far indicates there is still a desire to integrate some free eresources into public libraries' collection, even if these items are not seen a part of the collection. The focus is on a broad range of resources, including large scale, well-established projects such as Project Gutenberg as well as local digital efforts. Based on the survey results there may be growing interest in these types of resources as space and budgetary constraints increasingly affect collection development. Public libraries are interested in developing ebook collections from freely available resources as well as supplementing their existent subscription ebook collection.

Conversely, even as libraries express interest in adding such materials, there seems to be little activity towards making such materials a part of the libraries' ongoing collection development strategies. It is largely informal basis, rather than institutional policy, that dictates how libraries treat e-resources. This mixed relationship results in a haphazard incorporation of free e-resources. In addition, the general lack of a unified interface requires patrons to go to several different places on a library's website in order to find all relevant resources. This lack of cohesiveness reduces the library's effectiveness as a tool for discoverability. Acceptance of these types of items as parts of the collection is small and actual incorporation into the catalog does provide some challenges as noted above, but these impediments may be worthwhile to overcome. Previous research has shown that incorporation of free eresources into the catalog 
does increase use and the efforts of Boston Public Library to increase access to Project Gutenberg titles with Overdrive has created a benefit for the library; downloads of Project Gutenberg titles through Boston Public Library's website are being counted in circulation statistics. Boston Public Library's collaboration with Overdrive is a step in the right direction of removing barriers currently in place and increasing access points for public domain works. The current system norm of requiring logins to access public domain materials is untenable.

Most importantly, though, might be a re-envisioning of the problem, creating a way for libraries to easily upload their digital collections, create the metadata needed for cross-platform searching, and upload and download records.

In light of the current fiscal realities in libraries what better time to experiment with adding such resources to the collection? The current economic situation dictates that libraries practice frugality. Spending in the public sector is always scrutinized, but the current extreme duress means that budgets are being cut deeply. Libraries, by participating in disseminating works from Project Gutenberg, the Internet Archive, and the other freely accessible resources available benefit themselves by developing more diverse collections while also supporting projects that seek to stimulate the development of culture. 
References

Ball, R 2009, 'E-books in Practice: The Librarian's Perspective', Learned Publishing vol. 21, no. 1, pp. 18-22.

Baruchson-Arbib, S \& and Bronstein, J 2002, 'A View to the Future of the Library and Information Science Profession: a Delphi Study', Journal of the American Society for Information Science and Technology, vol. 53, no. 5, pp. $397-408$.

Beall, J 2009, 'Free Books: Loading Brief MARC Records for Open-Access Books in an Academic Library Catalog', Cataloging \& Classification Quarterly, vol. 47, no. 5, pp. 452 - 463.

Bedord, J 2009, 'Ebooks Hit Critical Mass: Where Do Libraries Fit With Oprah?', Online:

Exploring Technology and Resources for Information Professionals, vol. 33, no. 3, pp. 14-16, 18.

Blummer, B 2006 'E-books Revisited’, Internet Reference Services Quarterly, vol. 11, no. 2, pp. $1-13$.

Brown, C \& Meager, E (2008) 'Cataloging Free E-resources: Is it Worth the Investment?', Interlending \& Document Supply, vol. 36 no. 3, pp. 135 - 141.

Buczynski, J 2010 'Library E-books: Some Can't Find Them, Others Find Them and Don't Know What They Are', Internet Reference Services Quarterly, vol. 15, no. 1, pp. 11-19. 
Connaway, L \& Wicht, H 2007 'What Happened to the E-book Revolution?: The Gradual Integration of E-books into Academic Libraries', The Journal of Electronic Publishing, vol. 10, no. 3, viewed 1 November, 2010, http://dx.doi.org/10.3998/3336451.0010.302.

Creative Commons. 'Metrics: License Statistics', viewed 1 November 2010, http://wiki.creativecommons.org/Metrics/License_statistics.

Currie Susan \& lacobucci M (28 Sept 2010) ‘E-Readers and the Public Library', Online presentation, eBooks, eReaders \& libraries.

Darnton, R (12 February 2009) 'Google \& the Future of Books', New York Times Review of Books, viewed 1 November 2010, http://www.nybooks.com/articles/archives/2009/feb/12/google-the-future-of-books/

D’Elia, G, Jorgensen C \& Woelfel J 2001 'The Impact of the Internet on Public Library Use: An Analysis of the Current Consumer Market for Library and Internet Services', Journal of the American Society for Information Science and Technology vol. 53, no. 10, pp. 802-820.

Dierks, B (28 September 2010) 'Bringing E-book Readers to our Patrons: The Experience of the River Forest Public Library', Online presentation, eBooks, eReaders \& libraries.

Dillon, D (2001) 'E-Books: the University of Texas experience, Part 2', Library Hi Tech vol. 19, no. 4 , pp. $350-362$. 
Duncan, R (2010) 'Ebooks and Beyond: The Challenge for Public Libraries', Australasian Public Libraries and Information Services vol. 23, no. 2, pp. 44-55.

Eco, U (1997) 'The Future of the Book”

http://www.themodernword.com/eco/eco_future_of_book.html. From the July 1994

symposium "The Future of the Book," held at the University of San Marino. This essay

is also found in The Future of the Book (Berkeley; University of California Press, 1997).

Edited by Geoffrey Nunberg, the volume collects twelve papers from the symposium.

Fowler, G (29 June 2010) 'Libraries have a Novel Idea: Lenders Join Forces to Let Patrons

Check Out Digital Scans of Shelved Book Collections', The Wall Street Journal, viewed 1

November 2010,

http://online.wsj.com/article/NA_WSJ_PUB:SB100014240527487032797045753351930548846

32.html.

Gorman, M (2003) 'Collection Development in Interesting Times: a summary', Library

Collections, Acquisitions, \& Technical Services vol. 27, pp. 459 - 462.

Herring, M (2001) '10 Reasons Why the Internet Is no Substitute for a Library' American Libraries vol. 32, no. 4, pp. 76-78.

Hill, H \& Bossaller, J (7 October 2010) 'Barriers to Free Culture: An Examination of Public Libraries' Use of Internet Archives and Creative Commons Material', paper presented to Library Research Seminar V, College Park, Maryland, 6 - 9 October. 
Hutton, J (2008) 'Academic Libraries as Digital Gateways: Linking Students to the Burgeoning Wealth of Open Online Collections', Journal of Library Administration vol. 48, no. 3, pp. 495507.

Jones, E (2010) ‘Google Books as a General Research Collection’, Library Resources \& Technical Services vol. 54, no. 2, pp. 77-89.

Kahle, B (5 July 2009) 'Achievements for Humanity', viewed 1 November 2010, http://www.opencontentalliance.org/2009/07/05/achievements-for-humanity/.

Lebert, M (2008) ‘Project Gutenberg (1971-2008)', viewed November 1, 2010 http://www.gutenberg.org/ebooks/27045.

Levy, D (2003) 'Documents and Libraries: a Sociotechnical perspective' in Bishop, A, Van House, N \& Buttenfield B (ed.) Digital Library User: Social Practice in Design and Evaluation, Massachusetts Institute of Technology Press, Cambridge, MA.

Matthews, S (2010) '21st century blog', viewed 14 June 2010, http://21stcenturylibrary.wordpress.com/2010/12/21/a-\%E2\%80\%9Cperfectstorm\%E2\%80\%9D-is-battering-libraries/.

Miksa, F (1996) 'The Cultural Legacy of the 'Modern Library”, Journal of Education for Library and Information Science, vol. 37, no. 2, pp. 100-119..

Milliot, J (18 February 2008), 'Report Finds Growing Acceptance of Digital Books', Publishers 
Weekly, vol. 255, no. 7, p. 6.

Perrone, A (2009) ‘Electronic Book Collection Development in Italy: A Case Study’, IFLA Journal vol. 35 , no. 4 , pp. $305-312$.

Rodzvilla, J (2009) 'The Portable E-book: Issues with E-book Reading Devices in the Library', Serials vol. 22, no. 3, pp. S6-S10.

Soules, A (2009) 'The Shifting Landscape of E-books', New Library World vol. 110, no. 1/2, pp. 721.

Tedd, L (2005) 'E-books in Academic Libraries: An International Overview’, New Review of Academic Librarianship vol. 11, no. 1, pp. 57-79. 